\title{
PROJETO SOCIAL DE USUCAPIÃO ENGENHEIROS SEM FRONTEIRAS NÚCLEO DUQUE DE CAXIAS
}

\section{Emerson Fernandes Joy ${ }^{1}$ Júlio Cesar da Silva ${ }^{2}$}

Resumo: No Rio de Janeiro 50\% dos imóveis estão irregular. Se encontram nessa situação, alguns por não terem como arcar com os custos. A ONG - Engenheiros Sem Fronteiras Núcleo de Duque Caxias nasceu com o intuito de realizar projetos sociais visando a melhoria das comunidades da Baixada, e para tentar amenizar o problema criamos um projeto de Usucapião; que irá regulamentar imóvel pela posse prolongada e sem interrupção, durante o prazo legal, sabendo que a confecção de uma planta executada de forma particular por um profissional habilitado, teria um custo que a grande maioria dos moradores dos imóveis irregulares não poderiam arcar, em média o custo de um fica entorno de $R \$ 800,00$. Eliminaremos esse custo, somente sendo necessário o proprietário está em posse dos documentos necessários, fazer um cadastro, e assim iremos a residência levantar as características do imóvel, logo após confeccionar a planta no modelo do órgão do município responsável de prosseguir com o processo.

Palavras-chave: Usucapião; Legalização de Imóveis; Projeto Social.

\footnotetext{
${ }^{1}$ Engenharia Civil/UNIGRANRIO - Universidade do Grande Rio, Brasil. E-mail: emersonjoy@hotmail.com.

2 Engenharia Civil/UNIGRANRIO - Universidade do Grande Rio, Brasil. E-mail: jcesarop@unigranrio.edu.br.
} 